\title{
Non-metastatic Pancreatic Cancer: Resectable, Borderline Resectable, and Locally Advanced-Definitions of Increasing Importance for the Optimal Delivery of Multimodality Therapy
}

\author{
Douglas B. Evans, $\mathrm{MD}^{1}$, Ben George, $\mathrm{MD}^{2}$, and Susan Tsai, MD, MHS \\ ${ }^{1}$ Pancreatic Cancer Program, Department of Surgery, The Medical College of Wisconsin, Milwaukee, WI; ${ }^{2}$ Pancreatic \\ Cancer Program, Department of Medicine, The Medical College of Wisconsin, Milwaukee, WI
}

There is an evolving recognition that pancreatic cancer is a systemic disease at the time of diagnosis, even among patients with apparent localized disease. As a result, and supported by recent data demonstrating improved overall survival for patients who are treated with multimodality therapy as compared to surgery alone, greater attention has been focused on the optimal treatment sequencing of chemotherapy, chemoradiation, and surgery for patients with localized pancreatic cancer. ${ }^{1}$ Inherent in the decision to deliver all three modalities (or even just chemotherapy and surgery) to a patient with localized pancreatic cancer is the accurate identification of those who have potentially resectable disease at the time of diagnosis. Historically, resectability was determined at the time of operation; if the surgeon felt the tumor was resectable, the tumor was removed (often with a positive margin?) and the patient was declared to have had resectable disease. If at the time of operation the tumor was felt not to be resectable, the patient was declared to have locally advanced disease. In contrast, in order to conduct a clinical trial of neoadjuvant therapy, a pre-operative definition of resectable was needed to identify eligible patients for trial enrollment. ${ }^{2}$ This marked the first time that radiographic imaging (computed tomography [CT]) was used to preoperatively define and stage pancreatic cancer. $^{3}$ The benefit of such an objectively defined staging system for patients and physicians is obvious - the goals of therapy can be specifically defined at the time of diagnosis, once staging is completed. The goals of patients (and their

(C) Society of Surgical Oncology 2015

First Received: 12 May 2015;

Published Online: 30 June 2015

D. B. Evans, MD

e-mail: devans@mcw.edu treating physicians) who receive neoadjuvant treatment sequencing are eventual surgery and the potential for cure. To the extent that surgery is necessary (albeit usually not sufficient) for cure, patients who may be eligible for potentially curative surgery can be accurately defined; and those patients with locally advanced (nonoperable) disease are also identified. Among patients who have locally advanced pancreatic cancer as defined by preoperative imaging, surgery has historically been felt not to be possible.

However, it soon became clear that a gray-zone existed between the definitions of resectable and locally advanced pancreatic cancer. Borderline resectable disease was used to define those patients with arterial abutment and short segment venous (superior mesenteric-portal vein [SMVPV]) occlusion who, in the past, would have been considered locally advanced. ${ }^{4}$ However, after neoadjuvant therapy, such patients with responding disease (clinical benefit, improved imaging, and a decline in tumor marker profile) were being considered for surgery-hence the development of the borderline classification. ${ }^{5}$ Patients with borderline resectable pancreatic cancer are different from those with resectable disease in that they: (1) are at the highest possible risk for a positive margin of resection due to tumor-artery abutment, (2) require a more complex operation usually involving vascular resection and reconstruction; and (3) may be at higher risk for harboring radiographically occult distant metastatic disease. For these reasons, a longer period of induction therapy, often including chemotherapy followed by chemoradiation has been applied to this patient population. The chemoradiation portion of induction therapy is thought to be particularly important for those patients with arterial abutment in the hope of sterilizing at least the periphery of the tumor and thereby preventing a positive margin of resection. 
The manuscript by Sadot and colleagues from Memorial Sloan Kettering Cancer Center (MSKCC) in this issue of Annals of Surgical Oncology, now extends the possible role for surgery even further, to include patients with locally advanced disease. ${ }^{6}$ They applied a robust neoadjuvant systemic therapy (FOLFIRINOX), often followed by chemoradiation, and then reconsidered surgery in patients with responding disease. The objective response rate ( $>30 \%$ decrease in the largest dimension of the tumor) with FOLFIRINOX and chemoradiation was $29 \%$ and almost one-third of patients underwent surgical resection of their primary pancreatic cancer. Those patients who completed all therapy to include surgical resection of the pancreatic cancer appear to have a very favorable survival duration; median overall survival has not yet been reached. However, the precise anatomic definition of what was considered resectable, after induction therapy, was not clearly defined. The absence of an objective and reproducible definition of resectable makes it very difficult to translate the MSKCC report to less experienced centers world-wide. For example, the decision that a patient became operable was made at the author's multidisciplinary conference and on a case-by-case basis-the subjectivity of which impedes the generalizability of this approach. In contrast, the use of objectively defined criteria for pretreatment (and preoperative/post-neoadjuvant) staging (Table 1) has been espoused by our program and national consensus guidelines. ${ }^{7-9}$ The staging system used for clinical trial enrollment at the Medical College of Wisconsin is very similar to that of the NCCN (Table 2) which has been revised in 2015. An objective CT-based system for radiographic staging allows one to accurately identify the population of patients being treated and provides a system which may be reproducible at other institutions. For example, borderline resectable tumors can be surgically excised with the addition of vascular resection and reconstruction. ${ }^{10,11}$ Surgery is performed only after induction therapy (we prefer systemic therapy and chemoradiation before surgery), but importantly, surgery is part of the planned treatment program outlined to the patient at the time of diagnosis. In contrast, locally advanced tumors are considered unresectable in the absence of surgical excision of the celiac or superior mesenteric arteries-arteries which traditionally would not be removed at the time of pancreatectomy for pancreatic adenocarcinoma. With regard to the celiac artery, increasing experience has demonstrated the safety of celiac resection in carefully selected patients with tumors of the pancreatic body which have responded to induction therapy. ${ }^{12}$ However, the SMA is even more complicated and we are not yet at a point, with this disease, where we are resecting and reconstructing the SMA. The unresolved question is what degree of SMA abutment $\left(\leq 180^{\circ}\right)$ or encasement $\left(>180^{\circ}\right)$ should be approached surgically. Because the visceral arteries have a perineural sheath which envelopes them, there is often a plane of dissection between the adventitia of the artery and the neural sheath which allows for sharp dissection of the tumor off of the artery. Because complete $360^{\circ}$ encasement would require that one cuts through tumor to separate the SMA from the tumor, SMA encasement of this magnitude is considered non-operable at our institution. Our threshold for considering surgery following induction therapy, based on the degree of SMA encasement, is evolving and our current

TABLE 1 Medical College of Wisconsin CT-based staging of pancreatic cancer

\section{Resectable}

Tumor-artery relationship: no radiographic evidence of arterial abutment (celiac, SMA, or hepatic artery)

Tumor-vein relationship: tumor-induced narrowing, if present, is $\leq 50 \%$ of the circumference of the SMV, PV, or SMV-PV confluence

Borderline resectable

Artery: tumor abutment $\left(\leq 180^{\circ}\right.$ of the circumference) of SMA or celiac artery. Tumor abutment or short segment encasement $\left(>180^{\circ}\right)$ of the common hepatic artery

Vein: Tumor induced narrowing of $>50 \%$ of SMV, PV, or SMV-PV, or short segment occlusion of SMV, PV, SMV-PV with suitable PV (above) and SMV (below) to allow for safe vascular reconstruction.

Extrapancreatic findings: CT scan findings suspicious, but not diagnostic of, metastatic disease (for example, small indeterminate liver lesions which are too small to characterize)

Locally advanced

Artery: tumor encasement $\left(>180^{\circ}\right.$ of the circumference) of SMA or celiac artery

Vein (SM-PV confluence): occlusion of SMV, PV, or SMV-PV without suitable vessels above and below the tumor to allow for reconstruction (no distal or proximal target for vascular reconstruction)

Extrapancreatic findings: no evidence of peritoneal, hepatic, extra-abdominal metastases

Metastatic

Evidence of peritoneal or distant organ metastases

$S M A$ superior mesenteric artery; $S M V$ superior mesenteric vein; $P V$ portal vein; or $S M V$ - $P V$ superior mesenteric-portal vein 
TABLE 2 MCW vs. NCCN definitions for the staging of pancreatic adenocarcinoma

\begin{tabular}{|c|c|c|}
\hline Stage & MCW & NCCN 2015 \\
\hline \multicolumn{3}{|l|}{ Resectable } \\
\hline SMA, Celiac & No abutment & No abutment \\
\hline Hepatic Artery & No abutment & No abutment \\
\hline SMV-PV & $\leq 50 \%$ narrowing of SMV, PV, or SMV-PV & $\begin{array}{l}\text { No tumor contact or } \leq 180^{\circ} \text { contact without vein } \\
\text { contour irregularity }\end{array}$ \\
\hline \multicolumn{3}{|c|}{ Borderline resectable } \\
\hline SMA & $\leq 180^{\circ}$ (abutment) & $\leq 180^{\circ}$ (abutment) \\
\hline Celiac & $\leq 180^{\circ}$ (abutment) & $\begin{array}{l}\leq 180^{\circ} \text { (abutment) } \\
>180^{\circ} \text { without involvement of the aorta and amenable } \\
\text { to celiac resection (HA-GDA not involved)* }\end{array}$ \\
\hline Hepatic Artery & Abutment or short segment encasement $* *$ & Contact without extension to celiac or HA bifurcation** \\
\hline SMV-PV & $\begin{array}{l}>50 \% \text { narrowing of SMV, PV, SMV/PV or short } \\
\text { segment occlusion** }\end{array}$ & $\begin{array}{l}\text { Contact }>180^{\circ} \text { or contour irregularity or thrombosis and } \\
\text { reconstruction possible (suitable proximal and distal targets)** }\end{array}$ \\
\hline Other & $\begin{array}{l}\text { CT scan findings suspicious but not diagnostic of } \\
\text { metastatic disease }\end{array}$ & \\
\hline Locally advanced & & Unresectable \\
\hline SMA, Celiac & $>180^{\circ}$ (encasement) & $>180^{\circ}$ (encasement) \\
\hline SMV-PV & Occlusion without option for reconstruction & Unreconstructable SMV/PV \\
\hline
\end{tabular}

$S M A$ superior mesenteric artery; $S M V$ superior mesenteric vein; $P V$ portal vein; $S M V-P V$ superior mesenteric-portal vein; $H A-G D A$ hepatic artery-gastroduodenal artery; $N A$ not applicable

* Also considered locally advanced, refer to NCCN guidelines

** Amenable to reconstruction

thoughts on how to objectively classify the locally advanced patient are described in Table 3 .

In light of the improved response rates seen with current systemic therapies (FOLFIRINOX, gemcitabine-nab-paclitaxel, GTX), patients who were previously thought to have non-surgical disease are being reconsidered for surgery. Such patients have often received a lengthy course (4-6 months) of systemic therapy, often followed by chemoradiation, and are then found to have a good performance status with a low or normalized serum level of CA19-9. ${ }^{13}$ Essentially, these patients are "still standing" and often, the medical team does not know what to do with them-they have clearly responded to therapy, and options may include: a treatment break (rarely preferred by the asymptomatic patient with a normalized CA19-9); maintenance chemotherapy (however defined); or, consideration of surgery. Surgery is often considered because there are few other attractive options, complete histologic responses are rare with systemic therapy and chemoradiation (the primary tumor is likely to harbor viable cancer cells), and surgical resection of the primary tumor is thought to offer the only option for possible cure or long term survival. However, it is important to remember that such responding patients will likely realize a significant survival benefit even without surgery, as they have been pre-selected based on response to induction therapy. It therefore is critically important that surgery be applied only to carefully selected patients using objective criteria - and not because other therapies have been exhausted and the medical team is unsure of what to do next. Complex surgery for pancreatic cancer, often performed in older patients after a lengthy period of induction therapy, can be associated with significant risk for morbidity and mortality. The excellent results reported by Sadot and colleagues reflect the collective experience of some of the world's best surgeons at an internationally known cancer center; such results may not be reproducible at smaller centers with less experience.

Lastly, even if one adopts our suggestions in the attached tables for greater clarity and objectivity in the definitions used for borderline resectable and locally advanced pancreatic cancer, how does one define treatment response? Sadot and colleagues used CT imaging of the primary tumor $(>30 \%$ decrease in the greatest dimension of the primary tumor). However, the dense stroma associated with pancreatic cancer may result in little change on CT despite an excellent response at the cellular level. Furthermore, in patients with borderline resectable and locally advanced disease, FOLFIRINOX will not be the optimal initial treatment in all patients. We have all seen those patients who, for example, respond to gemcitabine and nab-paclitaxel after not responding to FOLFIRINOX. The ability to assess response in this complex patient 
TABLE 3 Comparison of the definitions used for borderline resectable and locally advanced pancreatic adenocarcinoma and a proposed classification (at time of diagnosis) of locally advanced disease into Type A and B based on potential for resection after neoadjuvant therapy

\begin{tabular}{|c|c|c|c|}
\hline \multirow{2}{*}{$\begin{array}{l}\text { Vascular structures which } \\
\text { determine the stage of } \\
\text { disease for localized } \\
\text { pancreatic cancer }\end{array}$} & \multirow[t]{2}{*}{ Borderline resectable } & \multicolumn{2}{|l|}{ Locally advanced } \\
\hline & & Type A & Type B \\
\hline $\begin{array}{l}\text { May be considered for } \\
\text { resection after } \\
\text { neoadjuvant therapy }\end{array}$ & Yes & Yes & No \\
\hline \multicolumn{4}{|l|}{ Tumor-artery anatomy } \\
\hline $\begin{array}{l}\text { SMA (usually pertains to a } \\
\text { tumor of the pancreatic } \\
\text { head/uncinate) }\end{array}$ & $\leq 180^{\circ}$ (abutment) & $>180^{\circ}$ encasement but $\leq 270^{\circ}$ & $>270^{\circ}$ \\
\hline $\begin{array}{l}\text { Celiac artery (usually } \\
\text { pertains to a tumor of the } \\
\text { pancreatic body) }\end{array}$ & $\leq 180^{\circ}$ (abutment) & $\begin{array}{l}>180^{\circ} \text { but does not extend to the } \\
\text { aorta and amenable to celiac } \\
\text { resection (with or without } \\
\text { reconstruction) }\end{array}$ & $\begin{array}{l}>180^{\circ} \text { and abutment/encasement } \\
\text { of the aorta }\end{array}$ \\
\hline $\begin{array}{l}\text { Hepatic artery (usually } \\
\text { pertains to a tumor of the } \\
\text { pancreatic neck/head) }\end{array}$ & $\begin{array}{l}\text { Short segment abutment/encasement } \\
\text { without extension to celiac artery or } \\
\text { HA bifurcation }\end{array}$ & $\begin{array}{l}>180^{\circ} \text { encasement with extension } \\
\text { to celiac artery and amenable to } \\
\text { vascular reconstruction }\end{array}$ & $\begin{array}{l}>180^{\circ} \text { encasement with extension } \\
\text { beyond bifurcation of proper } \\
\text { HA into right and left hepatic } \\
\text { arteries }\end{array}$ \\
\hline \multicolumn{4}{|l|}{ Tumor-vein anatomy } \\
\hline SMV-PV & $\begin{array}{l}>50 \% \text { narrowing of SMV, PV, SMV/ } \\
\mathrm{PV} \text {, or short segment occlusion, with a } \\
\text { distal and proximal target for } \\
\text { reconstruction }\end{array}$ & \multicolumn{2}{|c|}{$\begin{array}{l}\text { Occlusion without option for reconstruction: it would be very unusual } \\
\text { to have a situation where cavernous transformation of the portal vein } \\
\text { (which cannot be reconstructed-without a suitable distal [SMV] or } \\
\text { proximal }[\mathrm{PV}] \text { target for reconstruction) became operable }\end{array}$} \\
\hline
\end{tabular}

$S M A$ superior mesenteric artery; $S M V$ superior mesenteric vein; $P V$ portal vein; $S M V-P V$ superior mesenteric-portal vein; $H A$ hepatic artery; NA not applicable

TABLE 4 Proposed classification for response to neoadjuvant therapy

\begin{tabular}{|c|c|c|c|}
\hline Method of assessment & Responder & Stable disease & Nonresponder \\
\hline $\begin{array}{l}\text { Patient performance status (to } \\
\text { include pain assessment) }\end{array}$ & Improved & Not worse & Worse \\
\hline $\begin{array}{l}\text { Imaging of the primary tumor } \\
\text { (CT/MRI/PET, etc.) }\end{array}$ & Improved or no progression & No progression & $\begin{array}{l}\text { Local or distant } \\
\text { progression on cross- } \\
\text { sectional imaging }\end{array}$ \\
\hline $\begin{array}{l}\text { Biomarker Profile (including } \\
\text { CA19-9* and other emerging } \\
\text { biomarkers) }\end{array}$ & $\begin{array}{l}\text { Suggests treatment response (for example, a } \\
\text { normalization of CA19-9, other biomarkers } \\
\text { being developed) }\end{array}$ & Not worse & $\begin{array}{l}\text { Suggests progressive } \\
\text { disease }\end{array}$ \\
\hline $\begin{array}{l}\text { How to use the above } \\
\text { information }\end{array}$ & All three required to be a "Responder" & $\begin{array}{l}\text { All three required to be } \\
\text { considered as having } \\
\text { "Stable Disease" }\end{array}$ & $\begin{array}{l}\text { Any of the three would } \\
\text { define a } \\
\text { "Nonresponder"** }\end{array}$ \\
\hline
\end{tabular}

* CA19-9 must be measured when the serum bilirubin has normalized and such biomarkers should be assessed before treatment is initiated and at each re-staging evaluation

** Assuming clinical symptoms leading to a decline in performance status are not medically correctable

population is a significant contemporary challenge. Our proposed system for assessment of response to induction therapy is listed in Table 4. These definitions are being incorporated into our next generation of clinical trials as we further refine blood-based biomarkers, in addition to CA19-9, in an effort to provide a more rapid assessment of "response". This is something critically important for the majority of patients who, in the Sadot report, did not respond to a level thought appropriate to consider surgery by the multidisciplinary team at MSKCC. Indeed, as we celebrate the excellent survival of the patients who complete induction therapy and go on to surgery, we have more work to do. Specifically, for the majority of patients who remain nonresponders, we hope to develop (1) improved techniques (for example, molecular profiling) for determining the optimal therapy for each individual patient; and, (2) more rapid and sensitive techniques to assess response/ non-response thereby allowing for a change in therapy 
sooner than the traditional two months at which point most patients undergo repeat imaging. As multimodality therapy for pancreatic cancer continues to evolve, the integration of clearly defined staging systems and objective definitions of treatment response are critical. In the coming decade, an unprecedented number of novel therapies will be available for pancreatic cancer, and now is the time to standardize the definitions of stage and therapeutic response so that treatments and treatment sequencing can be accurately assessed.

\section{REFERENCES}

1. Tsai S, George B, Christians KK, Evans DB. Neoadjuvant chemotherapy and radiochemotherapy: is there a survival advantage for pancreatic cancer patients. In Beger HG, Nakao A, Neoptolemos JP, Peng SY, Sarr MG, eds. Pancreatic cancer, cystic neoplasms, and endocrine tumors: diagnosis and management. Oxford: Wiley-Blackwell, 2015

2. Evans DB, Rich TA, Byrd DR, Cleary KR, Connelly JH, Levin B, Charnsangavej C, Fenoglio CJ, Ames FC. Preoperative chemoradiation and pancreaticoduodenectomy for adenocarcinoma of the pancreas. Arch Surg 1992;127:1335-1339.

3. Fuhrman GM, Charnsangavej C, Abbruzzese JL, Martin RG, Fenoglio CF, Evans DB. Thin-section contrast enhanced computed tomography accurately predicts resectability of malignant pancreatic neoplasms. Am J Surg 1994;167: 104-113.

4. Varadhachary GR, Tamm EP, Crane C, Evans DB, Wolff RA. Borderline resectable pancreatic cancer. Curr Treat Options Gastroenterol. 2005;8(5):377-84.
5. Evans DB, Erickson BA, Ritch P. Borderline resectable pancreatic cancer: definitions and the importance of multimodality therapy. Ann Surg Oncol. 2010;17(11):2803-5.

6. Sadot E, Doussot A, O'Reilly E, et al. FOLFIRINOX induction therapy for stage III pancreatic adenocarcinoma. Ann Surg Oncol. (2014) 219(4):176

7. Appel BL, Tolat P, Evans DB, Tsai S. Current staging systems for pancreatic cancer. Cancer J. 2012;18(6):539-49.

8. Evans DB, Farnell MB, Lillemoe KD, Vollmer C Jr, Strasberg SM, Schulick RD. Surgical treatment of resectable and borderline resectable pancreas cancer: expert consensus statement. Ann Surg Oncol. 2009;16(7):1736-44.

9. Tempero MA, Malafa MP, Behrman SW, et al. Pancreatic adenocarcinoma, version 2.2014: featured updates to the NCCN guidelines. J Natl Compr Canc Netw. 2014;12(8):1083-93.

10. Pilgrim $\mathrm{CH}$, Tsai S, Evans DB, Christians KK. Mesocaval Shunting: A Novel Technique to Facilitate Venous Resection and Reconstruction and Enhance Exposure of the Superior Mesenteric and Celiac Arteries during Pancreaticoduodenectomy. J Am Coll Surg. 2013;217(3):e17-20

11. Pilgrim $\mathrm{CH}$, Tsai $\mathrm{S}$, Tolat $\mathrm{P}$, Patel $\mathrm{P}$, Rilling W, Evans DB, Christians KK. Optimal Management of the Splenic Vein at the Time of Venous Resection for Pancreatic Cancer: Importance of the Inferior Mesenteric Vein. J Gastrointest Surg. 2014;18(5): 917-21

12. Christians KK, Pilgrim CH, Tsai S, Ritch P, George B, Erickson B, Tolat P, Evans DB. Arterial resection at the time of pancreatectomy for cancer. Surgery. 2014;155(5):919-26

13. Christians KK, Tsai S, Mahmoud A, Ritch P, Thomas JP, Wiebe L, Kelly T, Erickson B, Wang H, Evans DB, George B. Neoadjuvant FOLFIRINOX for Borderline Resectable Pancreas Cancer: A New Treatment Paradigm? Oncologist. 2014;19(3):266-74. 